\title{
Effect of low-dose atrial natriuretic peptide in critically ill patients with acute kidney injury: a retrospective, single-center study with propensity-score matching
}

\author{
Keita Saito ${ }^{1 *}$, Shigehiko Uchino ${ }^{1}$, Tomoko Fujii ${ }^{2,3}$, Shinjiro Saito ${ }^{1}$, Masanori Takinami ${ }^{1}$ and Shoichi Uezono ${ }^{4}$
}

\begin{abstract}
Background: Acute kidney injury (AKI) is a major comorbidity in critically ill patients. Low-dose atrial natriuretic peptide (ANP) has been shown to effectively prevent acute kidney injury (AKI), especially in cardiovascular surgery patients. However, its treatment effects for AKI in critically ill patients are unclear.

Methods: This single-center, retrospective, observational study included patients with AKI diagnosed within 7 days after intensive care unit (ICU) admission during the period January 2010 to December 2017. We conducted a propensity-matched analysis to estimate the treatment effect of low-dose carperitide (a recombinant human ANP) on the clinical outcomes. The primary outcome was a composite of death, renal replacement therapy dependence, or no recovery from AKI (defined as an increase of the serum creatinine level to $\geq 200 \%$ of baseline) at hospital discharge.

Results: During the study period, 4479 adult patients were admitted to the ICU. We identified 1374 eligible patients with AKI diagnosed within 7 days after ICU admission. Among these patients, 346 (25.2\%) were treated with low-dose carperitide, with an average dose of $0.019 \mathrm{\mu g} \mathrm{kg}^{-1} \mathrm{~min}^{-1}$. The primary outcome occurred more often in the treatment group than in the control group ( $29.7 \%$ versus $23.4 \%$, respectively; $p=0.022$ ). After propensity score matching, characteristics of 314 patients from each group were well- balanced. Significant difference of the primary outcome, as seen with the full cohort, was no longer obtained; no benefit of carperitide was detected in the matched cohort (29.0\% versus 25.2\%; $p=0.281$ ).
\end{abstract}

Conclusions: Low-dose ANP showed no treatment effect in general critically ill patients who developed AKl.

Keywords: Atrial natriuretic peptide, Critically ill patients, AKI treatment

\section{Background}

Acute kidney injury (AKI) is one of the most common forms of organ damage encountered in the intensive care unit (ICU) and is associated with a high mortality rate [13]. Even after discharge from the ICU, the renal function of these patients is often not recovered to the premorbid level [4]. Progression to end-stage kidney disease of AKI patients was reported 3.1 times compared with non-AKI patients [5], which can affect quality of life, both physically and mentally [6]. Although many treatment strategies

\footnotetext{
* Correspondence: keishizu1314@mac.com

'Intensive Care Unit, Department of Anesthesiology, The Jikei University School of Medicine, 3-19-18, Nishi-Shinbashi Minato-ku, Tokyo 105-8471, Japan

Full list of author information is available at the end of the article
}

have been explored to date, none have proved to be effective in improving patient outcome [7].

Atrial natriuretic peptide (ANP) is an endogenous hormone that is released from the atrium. It plays an important role in fluid volume and blood pressure regulation, which has been studied for more than 30 years as a promising drug for AKI [8]. ANP affects the afferent arterioles of the glomerulus more strongly than the efferent arterioles, resulting in increased glomerular filtration rate (GFR) [9]. In addition, ANP exerts antiinflammatory effects by inhibiting nuclear factor- $\mathrm{kB}$ activation and cytokine production [10]. Studies have also reported that ANP can prevent lipopolysaccharideinduced oliguria by activating guanylyl cyclase $\mathrm{A}$ in proximal tubules and endothelial cells [11]. These

(c) The Author(s). 2020 Open Access This article is distributed under the terms of the Creative Commons Attribution 4.0 International License (http://creativecommons.org/licenses/by/4.0/), which permits unrestricted use, distribution, and 
properties make ANP attractive as a potential drug to prevent or treat AKI. Indeed, in patients with ischemic acute renal failure, ANP at an infusion rate of $0.05 \mu \mathrm{g}$ $\mathrm{kg}^{-1} \mathrm{~min}^{-1}$ induced an increase in renal blood flow and GFR by approximately $40 \%$ [12, 13]. Several systematic reviews and meta-analyses of ANP have been performed, which showed some beneficial effects of ANP including decreased serum creatinine levels and renal replacement therapy (RRT) requirement and decreased ICU and hospital length of stay [14-16]. However, most of the prior comparative studies looked at the preventive effects of ANP in the context of cardiovascular surgery [17-27] or contrast-induced nephropathy [28-30]. Limited information is available regarding the therapeutic effects of ANP in critically ill patients.

One meta-analysis found that ANP was associated with a trend toward increased mortality and more adverse events when administered in high doses, i.e. $>0.05 \mu \mathrm{g} / \mathrm{kg} /$ $\mathrm{min}$, possibly due to its induction of hypotension [14]. Another meta-analysis focused on low-dose ANP, i.e. $<0.05$ $\mu \mathrm{g} / \mathrm{kg} / \mathrm{min}$, found a significant decrease in RRT requirement with respect to both prevention and treatment of AKI in post-cardiac surgery patients [16]. However, the beneficial effects of low-dose ANP in patients with AKI in the ICU have not been examined sufficiently [31,32].

Here, we have assessed the therapeutic effect of lowdose ANP on outcomes of critically ill patients with AKI using a large database.

\section{Methods}

We conducted a single-center, retrospective, observational study in a 20-bed mixed ICU of an academic hospital in Tokyo, Japan. This study was conducted in accordance with the principles of the Declaration of Helsinki, and the ethical committee and institutional review board of the Jikei University Hospital approved the study protocol, No. (30-275 [9296]). Because of its retrospective, observational nature, the committee waived the need for written informed consent.

\section{Study setting and participants}

Patients who were admitted to the ICU from January 1, 2010, through December 31, 2017 were included screened. We identified patients $\geq 18$ years of age with $\geq 24 \mathrm{~h}$ of ICU stay who received a diagnosis of AKI within 7 days after ICU admission. Diagnosis of AKI was made according to the Acute Kidney Injury Work Group Kidney Disease: Improving Global Outcomes (KDIGO) definition [33]. Baseline creatinine level was defined as the mean outpatient serum creatinine value measured 7 to 365 days before hospital admission [34]. If baseline creatinine data were not available, we estimated the level according to the equation for Modification of Diet in Renal Disease (MDRD) for Japanese [35]. We excluded patients with end-stage kidney disease (ESKD), those who had kidney transplantation, and those with a history of urinary diversion. We also excluded patients who did not have AKI during the first 7 days in the ICU or those

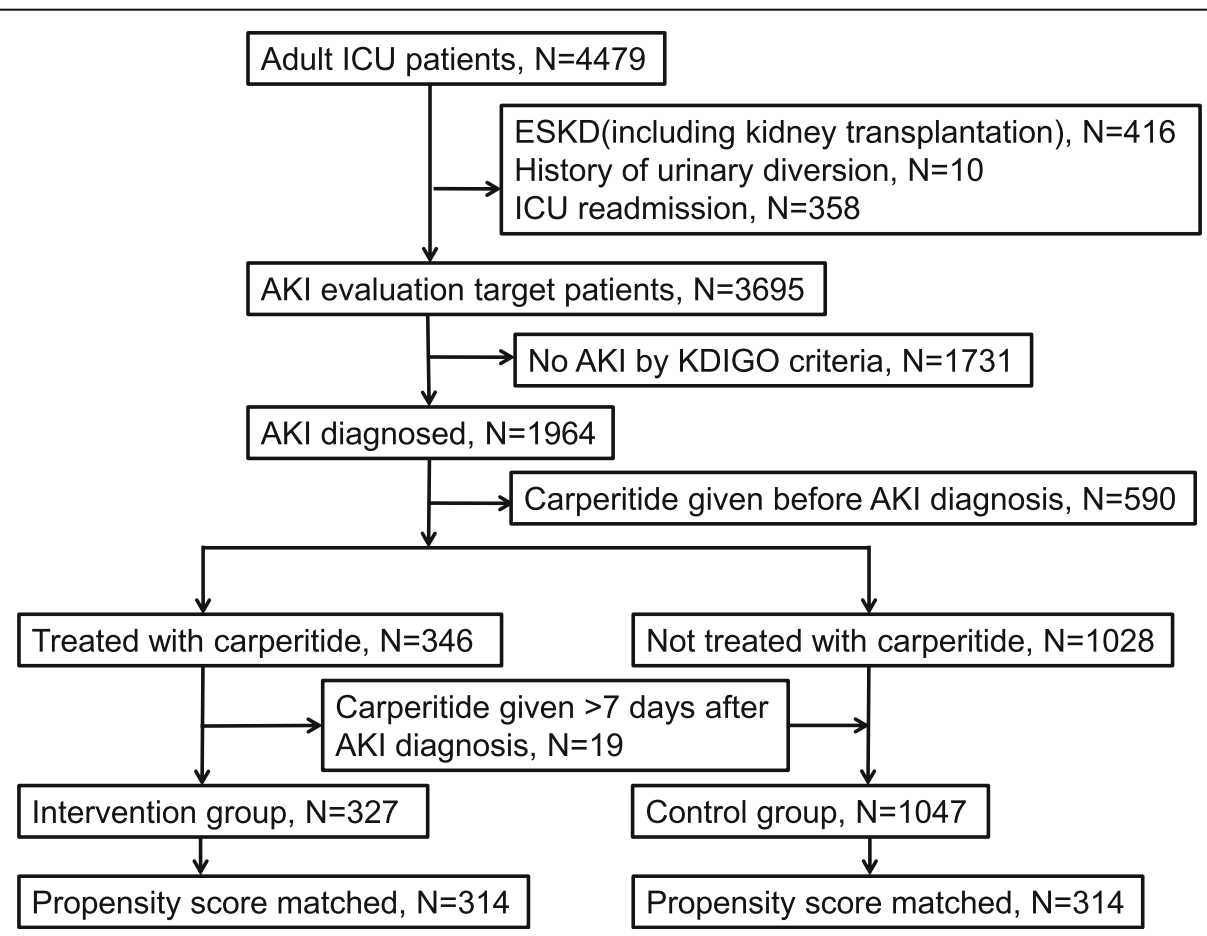

Fig. 1 Flow chart for study patients. AKI acute kidney injury, ESKD end-stage kidney disease, ICU intensive care unit, KDIGO Kidney Disease: Improving Global Outcomes 
who received ANP before the diagnosis of AKI. For patients with multiple admissions to the ICU during a single hospitalization period, only the first ICU admission was included.

In Japan, carperitide (HANP ${ }^{\oplus}$, Daiichi-Sankyo Pharmaceutical Inc., Tokyo, Japan), a recombinant human ANP, is the only ANP agent available commercially. We categorized eligible patients into those received carperitide within 7 days after AKI diagnosis (treatment group) and those did not receive it (control group). The timing and dosage of carperitide administration was determined at the discretion of the treating physician.

\section{Variables and outcomes}

Medical records were reviewed, and following data were collected: age, sex, height, body weight, ICU admission route (operating room [elective or emergency], emergency department, ward, other hospital), comorbidities (hematologic disease, metastatic cancer, immunosuppression, liver failure), primary damaged organ system (cardiovascular, respiratory, digestive, neurologic, other), presence of infection at ICU admission, use of noninvasive positive-pressure ventilation, hours of mechanical ventilation, Acute Physiology and Chronic Health Evaluation (APACHE) II score [36], serum creatinine level

Table 1 Patient demographic characteristics

\begin{tabular}{|c|c|c|c|c|}
\hline Characteristic & Overall & Control group & Treatment group & $p$ value \\
\hline Number of patients & 1374 & 1047 & 327 & \\
\hline Age (years) & $68(57-76)$ & $67(55-76)$ & $71(61-78)$ & $<0.001$ \\
\hline Male sex & $919(66.9)$ & $702(67.0)$ & $217(66.4)$ & 0.818 \\
\hline Height (cm) & $164(156-169)$ & $164(156-169)$ & $164(156-169)$ & 0.59 \\
\hline Body weight (kg) & $59(50-68)$ & $59(50-68)$ & $58(50-68)$ & 0.762 \\
\hline ICU admission route & & & & 0.055 \\
\hline OR (elective) & $404(29.4)$ & $291(27.8)$ & $113(34.6)$ & \\
\hline OR (emergency) & $223(16.2)$ & $177(16.9)$ & $46(14.1)$ & \\
\hline Emergency department & $336(24.5)$ & $270(25.8)$ & $66(20.2)$ & \\
\hline Ward & $375(27.3)$ & $284(27.1)$ & $91(27.8)$ & \\
\hline Other hospital & $36(2.6)$ & $25(2.4)$ & $11(3.4)$ & \\
\hline \multicolumn{5}{|l|}{ Comorbidity } \\
\hline Hematologic disease & $51(3.7)$ & $27(2.6)$ & $24(7.3)$ & $<0.001$ \\
\hline Metastatic cancer & $49(3.6)$ & $39(3.7)$ & $10(3.1)$ & 0.57 \\
\hline Immunosuppression & $123(9.0)$ & $86(8.2)$ & $37(11.3)$ & 0.086 \\
\hline Liver failure & $39(2.8)$ & $26(2.5)$ & $13(4.0)$ & 0.156 \\
\hline Primary damaged organ & & & & 0.117 \\
\hline Cardiovascular & $550(40.0)$ & $423(40.4)$ & $127(38.8)$ & \\
\hline Respiratory & $237(17.2)$ & $181(17.3)$ & $56(17.1)$ & \\
\hline Digestive & $239(17.4)$ & $187(17.9)$ & $52(15.9)$ & \\
\hline Neurologic & $212(15.4)$ & $147(14.0)$ & $65(19.9)$ & \\
\hline Other & $136(9.9)$ & $109(10.4)$ & $27(8.3)$ & \\
\hline Infection at ICU admission & $254(18.5)$ & $201(19.2)$ & $53(16.2)$ & 0.224 \\
\hline NPPV & $147(10.7)$ & $108(10.3)$ & 39 (11.9) & 0.411 \\
\hline MV duration (h) $(n=837)$ & $17.5(10.0-68.8)$ & $17.5(10.3-64.9)$ & $16.6(8.9-87.7)$ & 0.821 \\
\hline APACHE I| score & $18(14-22)$ & $18(14-22)$ & $18(14-23)$ & 0.384 \\
\hline \multicolumn{5}{|l|}{ Serum creatinine $(\mu \mathrm{mol} / \mathrm{L})$} \\
\hline Baseline & $73(63-86)$ & $73(62-82)$ & $76(66-99)$ & $<0.001$ \\
\hline ICU admission & $87(65-134)$ & $81(61-122)$ & $107(81-152)$ & $<0.001$ \\
\hline AKI diagnosis & $90(65-141)$ & $83(60-126)$ & $123(88-171)$ & $<0.001$ \\
\hline ICU-AKI (h) & $12.7(7.4-25.0)$ & $13.9(7.7-27.6)$ & $10.1(6.7-15.6)$ & $<0.001$ \\
\hline
\end{tabular}

Data are presented as no. (\%) or as median (interquartile range; 25 th-75th percentile)

AKI acute kidney injury, APACHE II Acute Physiology and Chronic Health Evaluation II, ICU intensive care unit, ICU-AKI h duration between ICU admission and AKI diagnosis, MV mechanical ventilation, NPPV noninvasive positive-pressure ventilation, $O R$ operating room 
(baseline, at ICU admission, and at AKI diagnosis), days from ICU admission to AKI diagnosis and days from AKI diagnosis to ANP administration.

The primary outcome was a composite of hospital mortality, the need of RRT or no recovery from AKI (defined as an increase of the serum creatinine level to $\geq 200 \%$ of baseline) at hospital discharge [37]. Secondary outcomes included the highest AKI stage during ICU stay (AKI max, AKI max-creatinine, AKI max-urine output), RRT use during ICU stay, ICU length of stay (LOS), hospital LOS, ICU mortality, and dialysis-free survival at hospital discharge. We also collected creatinine data at Day 1, Day 2, and Day 3 after AKI diagnosis and at ICU discharge; urine output at $24 \mathrm{~h}, 48 \mathrm{~h}$, and 72 $\mathrm{h}$ after AKI diagnosis; the median dose of carperitide administered and carperitide infusion period.

\section{Statistical methods}

Patient characteristics and outcomes were analyzed for differences between the two groups by the Mann-
Whitney $U$ test for continuous variables and the Fisher's exact test or chi square test for categorical variables. We created box plots for creatinine data (at Day 1, Day 2, and Day 3 after AKI diagnosis and at ICU discharge) and urine output (at $24 \mathrm{~h}, 48 \mathrm{~h}$, and $72 \mathrm{~h}$ after AKI diagnosis) divided by the two groups and compared them with the Mann-Whitney $U$ test.

We constructed a logistic model for carperitide administration to calculate the propensity score (PS) for each patient on the basis of the following variables: age, sex, body weight, height, source of admission to ICU, primary damaged organ system, APACHE II chronic health condition, APACHE II score, baseline serum creatinine level, days from ICU admission to AKI diagnosis, and serum creatinine level at AKI diagnosis. Propensity score matching using nearestneighbor method was performed in a 1-to-1 fashion between the treatment group and the control group using calipers of width equal to 0.2 of the standard deviation of the logit of the PS [38]. Covariate
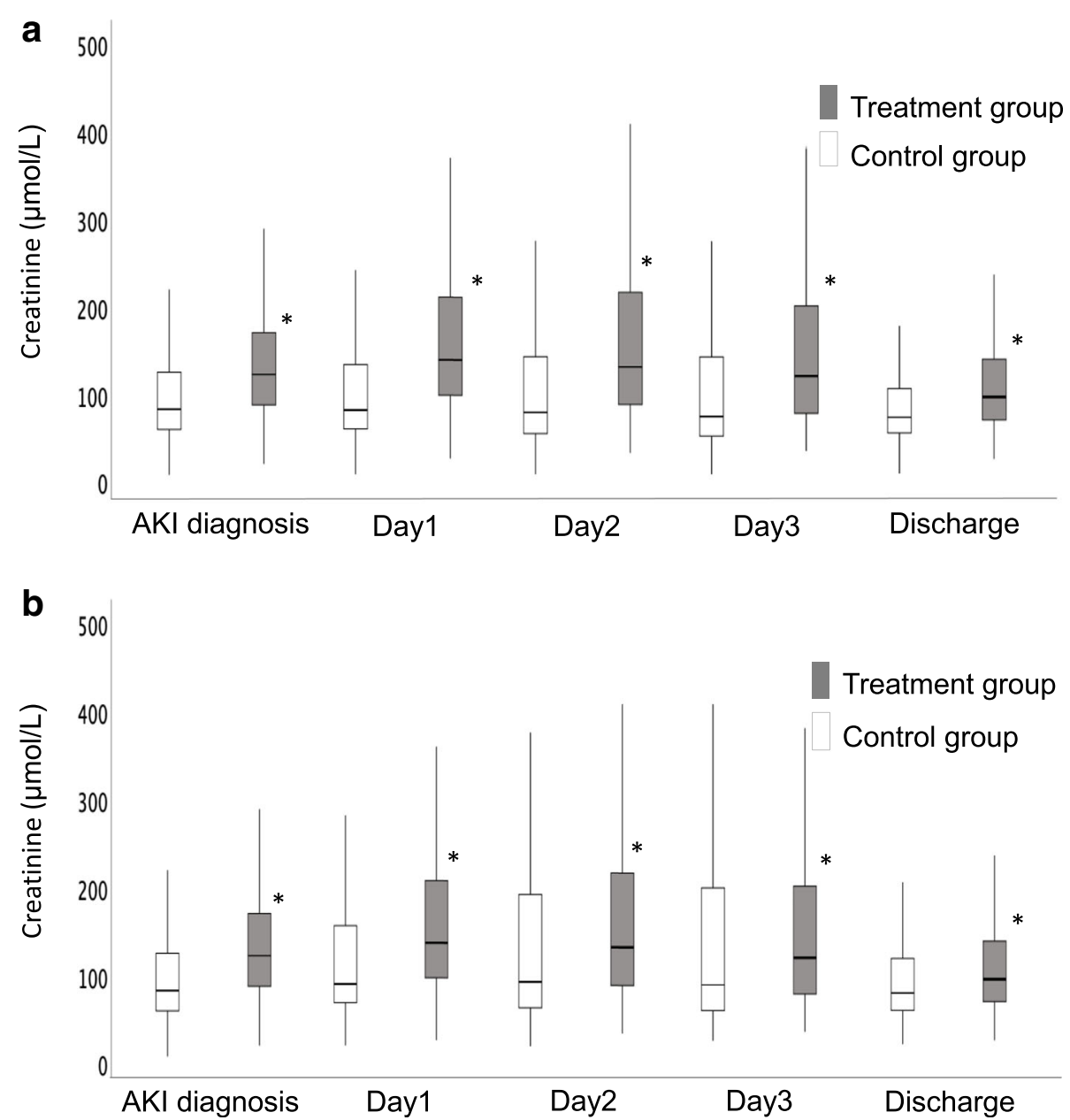

Fig. 2 Box plot for trends in serum creatinine levels at Day 1, Day 2, and Day 3 after AKI diagnosis and at ICU discharge for the full cohort (2a) and propensity-matched cohort (2b). AKl acute kidney injury. Gray box: treatment group, White box: control group 
balances before and after matching were checked by comparing standardized differences [39]. A standardized difference of $<0.10$ was considered to indicate successful balancing. Propensity score matching, calculation of standardized difference and survival analysis were performed using $\mathrm{R}$ (version 3.4.3; $\mathrm{R}$ Foundation for Statistical Computing, Vienna, Austria). We used 'Matching' package for the propensity score matched analysis. For the survival analysis, we used 'survival' package and 'survminer' package. All other statistical analyses were performed using SPSS (version 19.0; IBM Corp., Armonk, NY, USA). A two-sided $p$ value less than 0.05 was considered to have statistical significance.

\section{Additional analysis}

As post-hoc analysis, Kaplan-Meier survival curves of 90-day death were plotted and compared between groups using the log-rank test. We additionally performed an analysis fitting marginal structural model using inverse probability of treatment weights (IPTW) where standardised weights were estimated. We used 'ipw' package in $\mathrm{R}$ for the analysis.

\section{Results}

During the eight years of the study period, 4479 adult patients were admitted to the ICU. After excluding patients with ESKD including kidney transplantation, those with a history of urinary diversion, those with ICU readmission, those with no AKI by KDIGO criteria, and those treated with carperitide before AKI diagnosis, we included 1374 patients in this study (Fig. 1). Among these patients, 346 were treated with carperitide during their ICU stay. Because 19 patients were treated with carperitide $>7$ days after AKI diagnosis, the final treatment group consisted of 327 patients (23.8\%), and the control group consisted of $1047 \mathrm{pa}$ tients (76.2\%). Patient demographic and clinical data during ICU stay are listed in Table 1 . The treatment group was older (71 versus 67 years; $p<0.001)$ and had more hematologic disease $(7.3 \%$ versus $2.6 \% ; p<0.001)$. All serum creatinine levels (at baseline, ICU admission, and AKI diagnosis) were greater in the treatment group than in the control group (76 versus 73, 107 versus 81, 123 versus $83 \mu \mathrm{mol} / \mathrm{L}$ respectively; $p<0.001$ for all comparisons).

The creatinine level trend for the first 3 days and at discharge and the urinary output trend for the first $72 \mathrm{~h}$ after AKI diagnosis for the full cohort are shown in Figs. 2a and 3a,

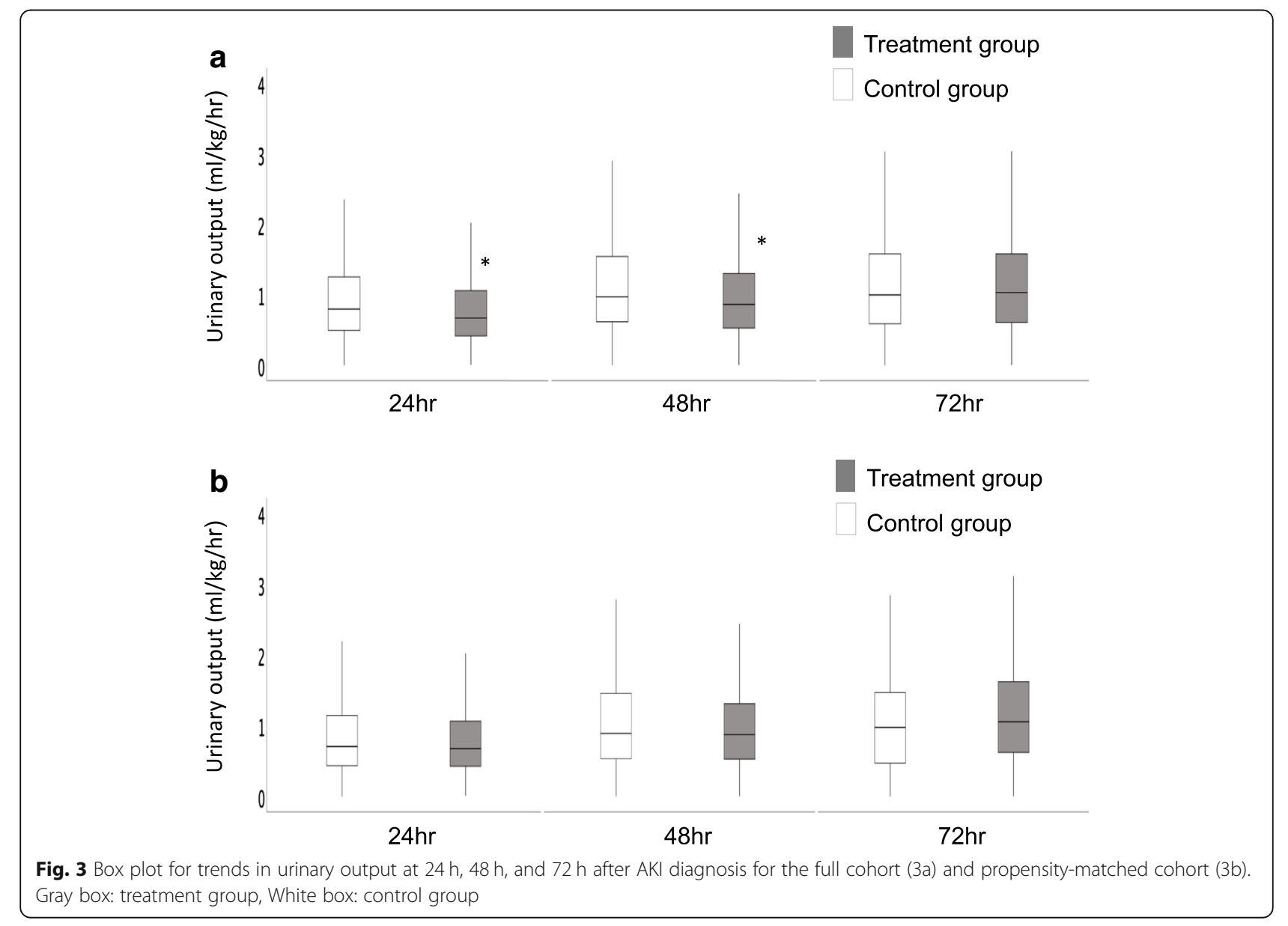


respectively. Creatinine levels were significantly greater for all days in the treatment group compared with the control group $(p<0.001)$. Urinary output was significantly greater at $24 \mathrm{~h}(p<0.001)$ and $48 \mathrm{~h}$ $(p=0.003)$ in the control group compared with the treatment group. It was not different between the two groups at $72 \mathrm{~h}(p=0.392)$.

Table 2 shows patient outcomes for the full cohort. The primary outcome was observed more frequently in the treatment group than in the control group $(29.7 \%$ versus $23.4 \%$; $p=0.022$ ). The ICU LOS (5.5 versus 2.8 days; $p<0.001$ ) and hospital LOS (44 versus 34 days; $p<$ 0.001 ) were also significantly longer in the treatment group. Values for ICU mortality and hospital mortality did not differ between the 2 groups (10.7\% versus 9.1\%; $p=0.379$ and $22.6 \%$ versus $19.7 \% ; p=0.247$, respectively). Use of RRT during the ICU stay was required significantly more often $(17.1 \%$ versus $10.1 \% ; p=0.001)$, and the highest AKI stages (AKI max-urine output, AKI max-creatinine, AKI max) were significantly worse in the treatment group. Figure 4a shows the Kaplan-Meier survival curves for the full cohort at 90 days. There was no difference in the survival curves between the two groups $(p=0.574)$. The median dose of carperitide was $0.019 \mu \mathrm{g} \mathrm{kg}^{-1} \mathrm{~min}^{-1}$ (interquartile range [IQR], 0.012$0.036 \mu \mathrm{g} \mathrm{kg}^{-1} \mathrm{~min}^{-1}$ ), and the carperitide infusion period was 2.05 days (IQR, 0.85-3.63 days). The median time from AKI diagnosis to carperitide administration was 0.65 days (IQR, $0.19-1.32$ days).

After PS matching, 314 patients from each group were matched, and the patient characteristics were wellbalanced (Table 3). The creatinine level trend for the first 3 days and at hospital discharge and the urinary output trend for the first $72 \mathrm{~h}$ after AKI diagnosis for the PS-matched population are shown in Figs. 2 and $3 \mathrm{~b}$ and b, respectively. Creatinine levels were significantly greater for the 3 days and ICU discharge in the treatment group compared with the control group $(p<0.001$ for Day 1, Day 2, and ICU discharge; $p=0.010$ for Day $3)$. However, urinary output did not differ between the 2 groups for all observation periods $(p=0.753, p=0.468$, $p=0.064$, respectively).

Table 2 Patient outcomes

\begin{tabular}{|c|c|c|c|c|}
\hline Variable & $\begin{array}{l}\text { Overall } \\
(n=1374)\end{array}$ & $\begin{array}{l}\text { Control group } \\
(n=1047)\end{array}$ & $\begin{array}{l}\text { Treatment group } \\
(n=327)\end{array}$ & $\overline{p \text { value }}$ \\
\hline Primary outcome & $342(24.9)$ & $245(23.4)$ & $97(29.7)$ & 0.022 \\
\hline In-hospital mortality & $280(20.4)$ & $206(19.7)$ & $74(22.6)$ & 0.247 \\
\hline RRT dependence & $33(2.4)$ & $24(2.3)$ & $9(2.8)$ & 0.635 \\
\hline No AKI recovery & $183(13.3)$ & $129(12.3)$ & $54(16.5)$ & 0.051 \\
\hline AKI max-urine output & & & & $<0.001$ \\
\hline No AKI & $254(18.5)$ & $199(19.0)$ & $55(16.8)$ & \\
\hline Stage 1 & $544(39.6)$ & $448(42.8)$ & $96(29.4)$ & \\
\hline Stage 2 & $403(29.3)$ & $279(26.6)$ & $124(37.9)$ & \\
\hline Stage 3 & $173(12.6)$ & $121(11.6)$ & $52(15.9)$ & \\
\hline AKI max-creatinine & & & & $<0.001$ \\
\hline No AKI & $577(42.0)$ & $523(50.0)$ & $54(16.5)$ & \\
\hline Stage 1 & $405(29.5)$ & $280(26.7)$ & $125(38.2)$ & \\
\hline Stage 2 & $145(10.6)$ & $87(8.3)$ & $58(17.7)$ & \\
\hline Stage 3 & $247(18.0)$ & $157(15.0)$ & $90(27.5)$ & \\
\hline AKI max & & & & $<0.001$ \\
\hline Stage 1 & $635(46.2)$ & $538(51.4)$ & $97(29.7)$ & \\
\hline Stage 2 & $436(31.7)$ & $312(29.8)$ & $124(37.9)$ & \\
\hline Stage 3 & $303(22.1)$ & $197(18.8)$ & $106(32.4)$ & \\
\hline RRT during ICU stay & $162(11.8)$ & $106(10.1)$ & $56(17.1)$ & 0.001 \\
\hline ICU LOS (days) & $3.4(1.9-6.6)$ & $2.8(1.8-5.6)$ & $5.5(3.6-9.6)$ & $<0.001$ \\
\hline ICU mortality & $130(9.5)$ & $95(9.1)$ & $35(10.7)$ & 0.379 \\
\hline Hospital LOS (days) & $37(21-66)$ & $34(20-62)$ & $44(26-76)$ & $<0.001$ \\
\hline Dialysis-free survival & $1070(77.9)$ & 823 (78.6) & $247(75.5)$ & 0.243 \\
\hline
\end{tabular}

Data are presented as no. (\%) or as median (interquartile range; 25 th-75th percentile)

$A K I$ acute kidney injury, AKI-max worst stage of AKI, ICU intensive care unit, LOS length of stay, No AKI recovery creatinine level $\geq 200 \%$ of baseline at hospital discharge, $R R T$ renal replacement therapy 

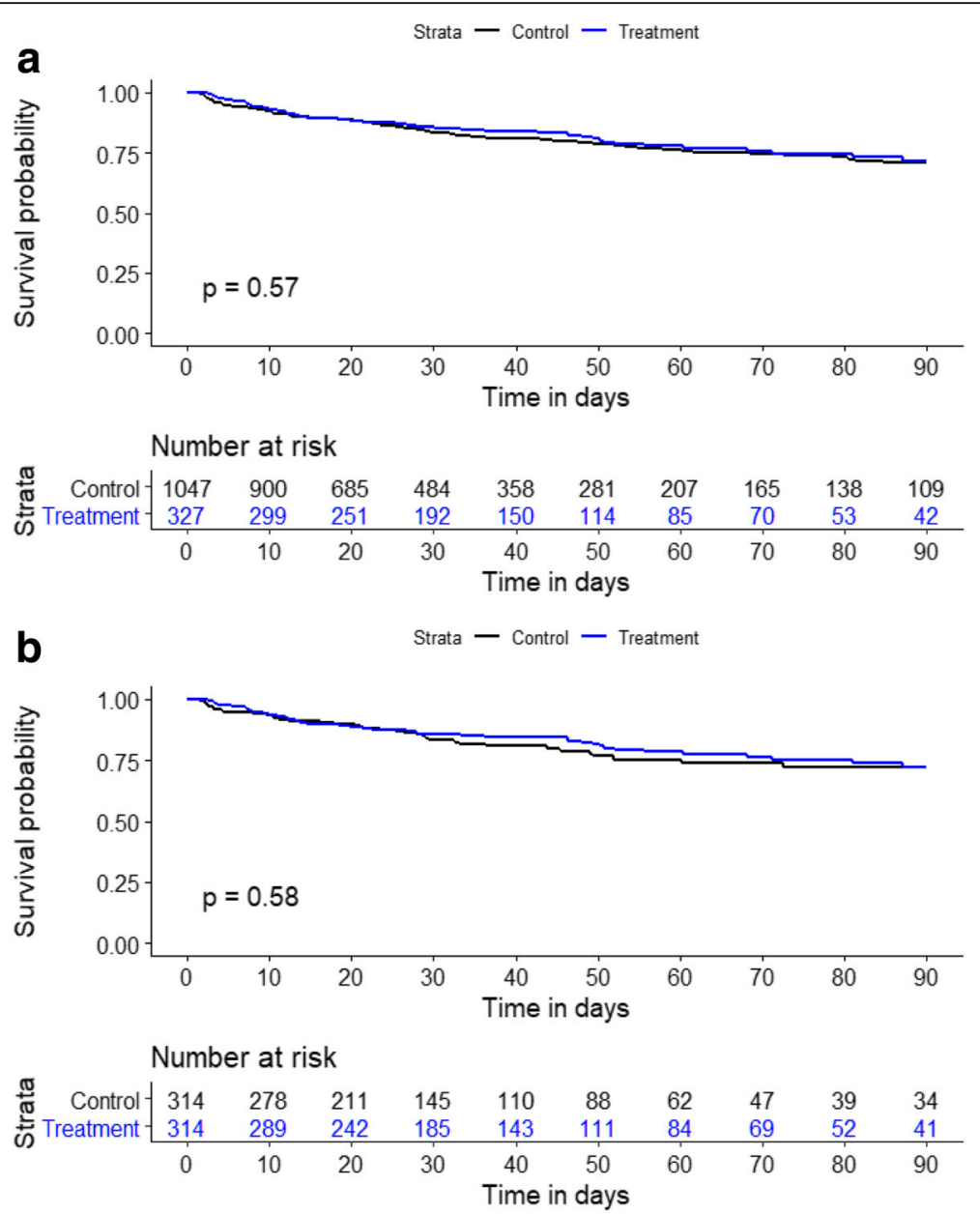

Fig. 4 Kaplan-Meier survival curves by the treatment group for the full cohort (4a) and propensity-matched cohort (4b) over 90 days

Significant difference of the primary outcome, as seen with the full cohort, was not detected in the matched cohort, although the value for the treatment group was numerically greater $(29.0 \%$ versus $25.2 \%$; $p=0.281$ ) (Table 4). ICU mortality and hospital mortality were also similar between the 2 groups $(10.5 \%$ versus $8.0 \% ; p=0.270,22.0 \%$ versus $19.1 \% ; p=0.374$, respectively). However, ICU LOS (5.6 versus 2.7 days; $p<0.001$ ) and hospital LOS (44 versus 35 days; $p=$ 0.001 ) were significantly longer in the treatment group. Use of RRT during the ICU stay was similarly required in the 2 groups $(16.6 \%$ versus $14.0 \% ; p=$ 0.375). The AKI max-urine output was also similar between the 2 groups. However, AKI max-creatinine and AKI max were significantly worse in the treatment group. Figure $4 \mathrm{~b}$ shows the Kaplan-Meier survival curves for the propensity-matched cohort at 90 days. There was no difference in the survival curves between the two groups $(p=0.575)$. The median dose of carperitide was $0.019 \mu \mathrm{g} \mathrm{kg}^{-1} \mathrm{~min}^{-1}$ (interquartile range [IQR], 0.012$0.036 \mu \mathrm{g} \mathrm{kg}^{-1} \mathrm{~min}^{-1}$ ), and the carperitide infusion period was 2.11 days (IQR, 0.90-3.61 days). The median time from AKI diagnosis to carperitide administration was 0.68 days (IQR, $0.19-1.33$ days).

As for the primary outcome, additional analysis using IPTW to fit a marginal structural model confirmed the robustness of the finding (risk difference, $0.8 \%$; 95\% CI, -5.6 to 7.1$)$.

\section{Discussion}

\section{Key findings}

In this study using PS matching, we studied the effect of low-dose ANP administration on a clinically important outcome, the composite of hospital mortality, RRT dependence at hospital discharge, and no AKI recovery, in general critically ill patients who developed AKI in the ICU. We found that the primary outcome was not affected by carperitide administration. Moreover, the highest AKI stage was worse in patients who were treated with carperitide, and ICU LOS and hospital LOS were longer in the carperitide treatment group. 
Table 3 Demographic characteristics for propensity-matched patients

\begin{tabular}{|c|c|c|c|}
\hline Characteristic & Control group & Treatment group & SMD \\
\hline Number of patients & 314 & 314 & \\
\hline Age (years) & $68(14)$ & $68(14)$ & 0.006 \\
\hline Male sex & $33(47)$ & $33(47)$ & $<0.001$ \\
\hline Height (cm) & $163(9)$ & $163(9)$ & 0.012 \\
\hline Body weight (kg) & $59(14)$ & $60(14)$ & 0.048 \\
\hline \multicolumn{4}{|l|}{ ICU admission route } \\
\hline OR (elective) & 118 (37.6) & $109(34.7)$ & 0.06 \\
\hline OR (emergency) & $40(12.7)$ & $46(14.6)$ & 0.056 \\
\hline Emergency department & $70(22.3)$ & $64(20.4)$ & 0.047 \\
\hline Ward & $77(24.5)$ & $84(26.8)$ & 0.051 \\
\hline Other hospital & $9(2.9)$ & $11(3.5)$ & 0.036 \\
\hline \multicolumn{4}{|l|}{ Comorbidity } \\
\hline Hematologic disease & $19(6.1)$ & $16(5.1)$ & 0.042 \\
\hline Metastatic cancer & $9(2.9)$ & $10(3.2)$ & 0.019 \\
\hline Immunosuppression & $36(11.5)$ & $31(9.9)$ & 0.052 \\
\hline Liver failure & $12(3.8)$ & $12(3.8)$ & $<0.001$ \\
\hline \multicolumn{4}{|l|}{ Primary damaged organ } \\
\hline Cardiovascular & $129(41.1)$ & $125(39.8)$ & 0.026 \\
\hline Respiratory & $57(18.2)$ & $53(16.9)$ & 0.034 \\
\hline Digestive & $46(14.6)$ & $51(16.2)$ & 0.044 \\
\hline Neurologic & $57(18.2)$ & $60(19.1)$ & 0.025 \\
\hline Other & $25(8.0)$ & $25(8.0)$ & $<0.001$ \\
\hline Infection at ICU admission & $53(16.9)$ & $50(15.9)$ & 0.026 \\
\hline NPPV & $35(11.1)$ & $37(11.8)$ & 0.020 \\
\hline MV duration (h) $(n=165)$ & $73.9(15.0)$ & $53.0(9.5)$ & 0.069 \\
\hline APACHE I| score & $19(7)$ & $19(7)$ & 0.006 \\
\hline \multicolumn{4}{|l|}{ Serum creatinine $(\mu \mathrm{mol} / \mathrm{L})$} \\
\hline Baseline & $92(74.3)$ & $91(46.9)$ & 0.012 \\
\hline ICU admission & $150(172.4)$ & 137 (99.9) & 0.092 \\
\hline AKI diagnosis & $149(158.2)$ & $148(99.9)$ & 0.007 \\
\hline \multicolumn{4}{|l|}{ AKI stage at diagnosis } \\
\hline Stage 1 & $258(82.2)$ & $250(79.6)$ & 0.064 \\
\hline Stage 2 & $29(9.2)$ & $37(11.8)$ & 0.083 \\
\hline Stage 3 & $27(8.6)$ & $27(8.6)$ & $<0.001$ \\
\hline ICU-AKI (h) & $14.9(0.7)$ & $13.9(0.7)$ & 0.063 \\
\hline
\end{tabular}

Data are presented as no. (\%) or as mean (standard deviation) AKI acute kidney injury, APACHE /I Acute Physiology and Chronic Health Evaluation II, ICU intensive care unit, ICU-AKI h duration between ICU admission and AKI diagnosis, OR operating room, SD standard deviation, SMD standard mean difference

\section{Comparison to previous studies}

In the medical literature, there are five studies [31, 4043] that have assessed the therapeutic effects of ANP; three studies used carperitide [31, 42, 43] and two studies used anaritide [40, 41]. Of the three meta-analyses, one meta-analysis pooled the effect of carperitide, anaritide, and urodilatin all together [14] and the other two focused on carperitide $[15,16]$. As carperitide is the only ANP that is commercially available in Japan, we assessed the effect of carperitide in this study.

To evaluate the therapeutic effect of anaritide (a 25amino-acid synthetic form of ANP), two large-scale randomized controlled trials (RCTs) were conducted in 1990s [40, 41]. Allgren et al. conducted a multicenter RCT of anaritide in 504 critically ill patients with acute tubular necrosis [40]. Study patients received a 24-h infusion of either anaritide $\left(0.2 \mu \mathrm{g} \mathrm{kg}^{-1} \mathrm{~min}^{-1}\right)$ or placebo. Although anaritide did not improve the overall rate of dialysis-free survival at 21 days after treatment, dialysisfree survival was improved in the anaritide group compared with the placebo group in the prospectively defined subgroup of 120 patients with oliguria $(<400 \mathrm{~mL} /$ day; $27 \%$ versus $8 \% ; p=0.008)$. On the basis of this subgroup analysis, they conducted a confirmatory doubleblind, multicenter RCT in patients with oliguric AKI [41]. However, they did not find a significant difference in dialysis-free survival ( $21 \%$ versus $15 \% ; p=0.22)$. It has been suggested that the high dose of ANP administered in those studies induced hypotension, which might have offset the therapeutic effect of ANP [14]. In our study, carperitide was administered in low doses; however, it did not improve renal function or RRT requirement or prognosis either.

Since 2000, two RCTs have examined the therapeutic effect of low-dose ANP on AKI [42, 43]. One study $\left(0.05 \mu \mathrm{g} \mathrm{kg}^{-1} \mathrm{~min}^{-1} ; N=61\right)$ showed that $21 \%$ of patients who underwent cardiac surgery in the ANP group required dialysis before or at day 21 compared with $47 \%$ in the placebo group $(p=0.009)$ [42]. The other RCT $\left(0.02 \mu \mathrm{g} \mathrm{kg}^{-1} \mathrm{~min}^{-1} ; N=77\right)$ also studied patients who underwent cardiovascular surgery and showed that, although ANP increased urine output, it did not significantly improve renal function or RRT requirement compared with placebo [43]. Both RCTs were of low quality with small sample size, and studied only patients undergoing cardiovascular surgery. In addition, one study was conducted before consensus definitions of AKI were developed [42].

Moreover, although three of the four RCTs have dialysis-free survival at 21 days after treatment on the primary outcome [40-42], one RCT has made the renal outcome changes such as creatinine change and urine volume change on the primary outcome [43]. We adopted patient-centered outcome as the primary outcome which was the composite of hospital mortality, the need of RRT or no recovery from AKI at hospital discharge.

With respect to general ICU patients who developed AKI, to the best of our knowledge, there is only one observational study that evaluated the therapeutic effect of low-dose ANP 
Table 4 Outcomes for propensity-matched patients

\begin{tabular}{|c|c|c|c|c|}
\hline Variable & $\begin{array}{l}\text { Overall } \\
(n=628)\end{array}$ & $\begin{array}{l}\text { Control group } \\
(n=314)\end{array}$ & $\begin{array}{l}\text { Treatment group } \\
(n=314)\end{array}$ & $p$ value \\
\hline Primary outcome & $170(27.1)$ & $79(25.2)$ & $91(29.0)$ & 0.281 \\
\hline In-hospital mortality & $129(20.5)$ & $60(19.1)$ & $69(22.0)$ & 0.374 \\
\hline RRT dependence & $22(3.5)$ & $13(4.1)$ & $9(2.9)$ & 0.385 \\
\hline No AKI recovery & $93(14.8)$ & $42(13.4)$ & $51(16.2)$ & 0.312 \\
\hline AKI max-urine output & & & & 0.123 \\
\hline No AKI & $120(19.1)$ & $66(21.0)$ & $54(17.2)$ & \\
\hline Stage 1 & $202(32.2)$ & $110(35.0)$ & $92(29.3)$ & \\
\hline Stage 2 & $212(33.8)$ & $95(30.3)$ & $117(37.3)$ & \\
\hline Stage 3 & $94(15.0)$ & $43(13.7)$ & $51(16.2)$ & \\
\hline AKI max-creatinine & & & & $<0.001$ \\
\hline No AKI & $186(29.6)$ & $135(43.0)$ & $51(16.2)$ & \\
\hline Stage 1 & $213(33.9)$ & $92(29.3)$ & $121(38.5)$ & \\
\hline Stage 2 & $89(14.2)$ & $31(9.9)$ & $58(18.5)$ & \\
\hline Stage 3 & $140(22.3)$ & $56(17.8)$ & $84(26.8)$ & \\
\hline AKI max & & & & $<0.001$ \\
\hline Stage 1 & $236(37.6)$ & $142(45.2)$ & $94(29.9)$ & \\
\hline Stage 2 & $225(35.8)$ & $105(33.4)$ & $120(38.2)$ & \\
\hline Stage 3 & $167(26.6)$ & $67(21.3)$ & $100(31.8)$ & \\
\hline RRT during ICU stay & $96(15.3)$ & $44(14.0)$ & $52(16.6)$ & 0.375 \\
\hline ICU LOS (days) & $3.8(2.3-6.9)$ & $2.7(1.7-4.8)$ & $5.6(3.7-9.6)$ & $<0.001$ \\
\hline ICU mortality & $58(9.2)$ & $25(8.0)$ & $33(10.5)$ & 0.27 \\
\hline Hospital LOS (days) & $40(23-69)$ & $35(21-62)$ & $44(26-76)$ & 0.001 \\
\hline Dialysis-free survival & $482(76.8)$ & $243(77.4)$ & $239(76.1)$ & 0.706 \\
\hline
\end{tabular}

Data are presented as no. (\%) or as median (interquartile range; 25th-75th percentile)

$A K I$ acute kidney injury, AKI max worst stage of AKI, ICU intensive care unit, LOS length of stay, MV mechanical ventilation, No AKI recovery creatinine level $\geq 200 \%$ of baseline at hospital discharge, NPPV noninvasive positive-pressure ventilation, $R R T$ renal replacement therapy

$\left(0.028 \mu \mathrm{g} \mathrm{kg}^{-1} \mathrm{~min}^{-1}\right)$, which found no therapeutic effect of ANP [31]. Although that study was a multicenter, prospective, observational study, the number of patients treated with ANP was small $(N=63)$, suggesting a lack of power to detect significance. Although the present study was a single-center study, the number of patients treated with low-dose ANP $\left(0.019 \mu \mathrm{g} \mathrm{kg}^{-1} \mathrm{~min}^{-1}\right)$ was more than 300 , the largest sample size among all low-dose ANP studies [31, 42, 43].

\section{Significance and implications}

Previous five studies examining the therapeutic effects of any dose of ANP found inconsistent benefits [17-30]. The KDIGO clinical practice guideline for AKI suggests not using ANP to treat AKI and requires further trials of ANP at low doses [33]. Recent meta-analysis focusing on low-dose ANP implied its beneficial therapeutic effects in patients with cardiac surgery [16]; however, two recent observational studies, including the present study, found that low-dose ANP did not change the outcome of critically ill patients who developed AKI [31]. The difference might be due to patient background (cardiovascular versus general ICU patients), or study design (randomized versus observational). Although ANP administration is pharmacologically effective in increasing the GFR [9], this effect might be offset by a hypotensive side effect [31]. Critically ill patients with AKI (e.g., septic shock) might be more prone to the vasodilative effect of lowdose ANP compared to patients with ANP administered prophylactically or those with less critical conditions (e.g., elective cardiovascular surgery) [16, 42]. Although the two recent studies in critically ill patients were observational studies, the lack of effectiveness of ANP causes a stir on the use of ANP for AKI in the critically ill.

\section{Study strengths and limitations}

The present study has several strengths. The number of patients who were treated with ANP was the largest among all low-dose ANP studies [31, 42, 43]. The findings will be more applicable to patients in the ICU than those from previous studies in cardiac surgery patients. Furthermore, we evaluated physiological outcomes (changes in serum creatinine levels and urine output) as well as patient-centered outcomes (composite of mortality, RRT 
dependence, and nonrecovery of renal function at hospital discharge). Because of the limited evidence in the literature for a therapeutic effect of low-dose ANP, the present study should provide valuable information with respect to understanding the use of ANP for the management of AKI in the ICU.

The present study also has several limitations. First, this was a single-center study whose results might be influenced by the local clinical practice and may limit the generalizability of its findings. Second, we did not collect data on blood pressure or use of vasopressors. Third, although we used PS matching to minimize the bias due to confounding factors, the results of PS matching are generalizable only among those in the range of PS values included in the analysis, and they may not be applicable to those who are out of this range. Moreover, there might have been unmeasured confounders that were not addressed in the PS model.

\section{Conclusions}

In the present retrospective observational study in critically ill patients with AKI, we found no therapeutic effect of low-dose ANP. Considering the currently available evidence, ANP should not be used to treat AKI in critically ill patients.

\begin{abstract}
Abbreviations
AKI: Acute kidney injury; ANP: Atrial natriuretic peptide; APACHE: Acute Physiology and Chronic Health Evaluation; CIAKI: Contrast-induced AKI; CKD: Chronic kidney disease; GFR: Glomerular filtration rate; ICU: Intensive care unit; KDIGO: Kidney Disease: Improving Global Outcomes; MAP: Mean arterial pressure; PS: Propensity score; RCT: Randomized controlled trial; RRT: Renal replacement therapy; SAPS: Simplified Acute Physiology Score
\end{abstract}

\section{Acknowledgements}

Not applicable.

\section{Authors' contributions}

KS, TF, S Uchino, and MT participated in the design of the study. KS collected the data. KS, SS, TF, and S Uchino analyzed the data. KS, TF, and S Uchino drafted the manuscript. MT and S Uezono reviewed and improved the manuscript. All authors read and approved the final manuscript.

\section{Funding}

All authors have not received funding relevant for this study.

\section{Availability of data and materials}

The study data supporting the conclusions of this article are available from the corresponding author. The study data will be provided by request.

\section{Ethics approval and consent to participate}

This study was approved by our institutional review board of the Jikei University School of Medicine, Ethics Committee No. (30-275 [9296]). As this was a retrospective study, the need for informed consent was waived.

\section{Consent for publication}

Not applicable.

\section{Competing interests}

All authors report no competing interests.

\section{Author details}

${ }^{1}$ Intensive Care Unit, Department of Anesthesiology, The Jikei University School of Medicine, 3-19-18, Nishi-Shinbashi Minato-ku, Tokyo 105-8471, Japan. ${ }^{2}$ The Australian and New Zealand Intensive Care Research Centre, Monash University, 553 St Kilda Rd, Melbourne, VIC 3004, Australia. ${ }^{3}$ Graduate School of Medicine, Kyoto University, Yoshida-Honmachi, Sakyo-ku, Kyoto 606-8501, Japan. ${ }^{4}$ Department of Anesthesiology, The Jikei University School of Medicine, 3-19-18, Nishi-Shinbashi Minato-ku, Tokyo 105-8471, Japan.

Received: 10 June 2019 Accepted: 21 January 2020

Published online: 30 January 2020

\section{References}

1. Bellomo R, Kellum JA, Ronco C. Acute kidney injury. Lancet. 2012;380:75666.

2. Brochard L, Abroug F, Brenner M, Broccard AF, Danner RL, Ferrer M, et al. ATS/ ERS/ESICM/SCCM/SRLF Ad Hoc Committee on Acute Renal Failure. An official ATS/ERS/ESICM/SCCM/SRLF statement: prevention and management of acute renal failure in the ICU patient: an international consensus conference in intensive care medicine. Am J Respir Crit Care Med. 2010;181:1128-55.

3. Uchino S, Kellum JA, Bellomo R, Doig GS, Morimatsu H, Mogera S, et al. Beginning and ending supportive therapy for the kidney (BEST kidney) investigators. Acute renal failure in critically ill patients: a multinational, multicenter study. JAMA. 2005;294:813-8.

4. Pannu N, James M, Hemmelgarn BR, Dong J, Tonelli M, Klarenbach S. Alberta Kidney Disease Network. Modification of outcomes after acute kidney injury by the presence of CKD. Am J Kidney Dis. 2011;58:206-13.

5. Coca SG, Singanamala S, Parikh CR. Chronic kidney disease after acute kidney injury: a systematic review and meta-analysis. Kidney Int. 2012;81: 442-8.

6. Zalai D, Szeifert L, Novak M. Psychological distress and depression in patients with chronic kidney disease. Semin Dial. 2012;25:428-38.

7. Molitoris BA, Okusa MD, Palevsky PM, Kimmel PL, Star RA. Designing clinical trials in acute kidney injury. Clin J Am Soc Nephrol. 2012;7:842-3.

8. Levin ER, Gardner DG, Samson WK. Natriuretic peptides. N Engl J Med. 1998; 339:321-8.

9. Marin-Grez M, Fleming JT, Steinhausen M. Atrial natriuretic peptide causes pre-glomerular vasodilatation and post-glomerular vasoconstriction in rat kidney. Nature. 1986;324:473-6.

10. Ladetzki-Baehs K, Keller M, Kiemer AK, Koch E, Zahler S, Wendel A, et al. Atrial natriuretic peptide, a regulator of nuclear factor-kappaB activation in vivo. Endocrinology. 2007;148:332-6.

11. Kitamura H, Nakano D, Sawanobori Y, Asaga T, Yokoi H, Yanagita M, et al. Guanylyl cyclase a in both renal proximal tubular and vascular endothelial cells protects the kidney against acute injury in rodent experimental endotoxemia models. Anesthesiology. 2018;129:296-310.

12. Valsson F, Ricksten SE, Hedner T, Lundin S. Effects of atrial natriuretic peptide on acute renal impairment in patients with heart failure after cardiac surgery. Intensive Care Med. 1996;22:230-6.

13. Swärd K, Valson F, Ricksten SE. Long-term infusion of atrial natriuretic peptide (ANP) improves renal blood flow and glomerular filtration rate in clinical acute renal failure. Acta Anaesthesiol Scand. 2001;45:536-42.

14. Nigwekar SU, Navaneethan SD, Parikh CR, Hix JK. Atrial natriuretic peptide for management of acute kidney injury: a systematic review and metaanalysis. Clin J Am Soc Nephrol. 2009:4:261-72.

15. Mitaka C, Kudo T, Haraguchi G, Tomita M. Cardiovascular and renal effects of carperitide and nesiritide in cardiovascular surgery patients: systematic review and meta-analysis. Crit Care. 2011;15:R258.

16. Yamada H, Doi K, Tsukamoto T, Kiyomoto H, Yamashita K, Yanagita M, et al. Low-dose atrial natriuretic peptide for prevention or treatment of acute kidney injury: a systematic review and meta-analysis. Crit Care. 2019;23:41.

17. Izumi K, Eishi K, Yamachika S, Hashizume K, Tada S, Yamane K, et al. The efficacy of human atrial natriuretic peptide in patients with renal dysfunction undergoing cardiac surgery. Ann Thorac Cardiovasc Surg. 2008; 14:294-302.

18. Yoshitake I, Sezai A, Hata M, Niino T, Unosawa S, Wakui S, et al. Low-dose atrial natriuretic peptide for chronic kidney disease in coronary surgery. Ann Thorac Cardiovasc Surg. 2011;17:363-8.

19. Sezai A, Nakata K, lida M, Yoshitake I, Wakui S, Hata H, et al. Results of lowdose carperitide infusion in high-risk patients undergoing coronary artery bypass grafting. Ann Thorac Surg. 2013;96:119-26. 
20. Sezai A, Shiono M, Orime $Y$, Hata H, Hata M, Negishi N, et al. Low-dose continuous infusion of human atrial natriuretic peptide during and after cardiac surgery. Ann Thorac Surg. 2000;69:732-8.

21. Sezai A, Nakata K, lida M, Yoshitake I, Wakui S, Hata H, et al. Early results of human atrial natriuretic peptide infusion in non-dialysis patients with chronic kidney disease undergoing isolated coronary artery bypass grafting: the NU-HIT trial for CKD-II. Ann Thorac Cardiovasc Surg. 2014;20:217-22.

22. Sezai A, Hata M, Wakui S, Shiono M, Negishi N, Kasamaki Y, et al. Efficacy of low-dose continuous infusion of alpha-human atrial natriuretic peptide (hANP) during cardiac surgery: possibility of postoperative left ventricular remodeling effect. Circ J. 2006;70:1426-31.

23. Sezai A, Hata M, Wakui S, Niino T, Takayama T, Hirayama A, et al. Efficacy of continuous low-dose hANP administration in patients undergoing emergent coronary artery bypass grafting for acute coronary syndrome. Circ J. 2007;71:1401-7.

24. Mitaka C, Kubo T, Jibiki M, Sugano N, Inoue Y, Makita K, et al. Effects of human atrial natriuretic peptide on renal function in patients undergoing abdominal aortic aneurysm repair. Crit Care Med. 2008;36:745-51.

25. Sezai A, Hata M, Niino T, Yoshitake I, Unosawa S, Wakui S, et al. Results of lowdose human atrial natriuretic peptide infusion in nondialysis patients with chronic kidney disease undergoing coronary artery bypass grafting: the NU-HIT (Nihon University working group study of low-dose HANP infusion therapy during cardiac surgery) trial for CKD. J Am Coll Cardiol. 2011;58:897-903.

26. Sezai A, Hata M, Niino T, Yoshitake I, Unosawa S, Wakui S, et al. Influence of continuous infusion of low-dose human atrial natriuretic peptide on renal function during cardiac surgery: a randomized controlled study. J Am Coll Cardiol. 2009;54:1058-64.

27. Sezai A, Hata M, Niino T, Yoshitake I, Unosawa S, Wakui S, et al. Continuous low-dose infusion of human atrial natriuretic peptide in patients with left ventricular dysfunction undergoing coronary artery bypass grafting: the NUHIT (Nihon University working group study of low-dose human ANP infusion therapy during cardiac surgery) for left ventricular dysfunction. J Am Coll Cardiol. 2010;55:1844-51.

28. Kurnik BR, Allgren RL, Genter FC, Solomon RJ, Bates ER, Weisberg LS Prospective study of atrial natriuretic peptide for the prevention of radiocontrast-induced nephropathy. Am J Kidney Dis. 1998;31:674-80.

29. Morikawa S, Sone T, Tsuboi H, Mukawa H, Morishima I, Uesugi M, et al. Renal protective effects and the prevention of contrast-induced nephropathy by atrial natriuretic peptide. J Am Coll Cardiol. 2009;53:1040-6.

30. Okumura N, Hayashi M, Imai E, Ishii H, Yoshikawa D, Yasuda Y, et al. Effects of carperitide on contrast-induced acute kidney injury with a minimum volume of contrast in chronic kidney disease patients. Nephron Extra. 2012; 2:303-10.

31. Fujii T, Sato T, Uchino S, Doi K, Iwami T, Kawamura T, JAKID study group. Human atrial natriuretic peptide for acute kidney injury in adult critically ill patients: a multicenter prospective observational study. J Crit Care. 2018;18:31100-6.

32. Ricksten SE, Bagshaw SM. Atrial natriuretic peptide for treatment of acute kidney injury (AKI) - initiate an optimal dose early. J Crit Care. 2018;18: 31778-7.

33. Kellum JA, Lameire N, Aspelin P, Barsoum RS, Burdmann EA, Goldstein SL, et al. Kidney disease: improving global outcomes (KDIGO) acute kidney injury work group. KDIGO clinical practice guideline for acute kidney injury. Kidney Int Suppl. 2012;2:1-138.

34. Siew ED, Ikizler TA, Matheny ME, Shi Y, Schildcrout JS, Danciu I, et al. Estimating baseline kidney function in hospitalized patients with impaired kidney function. Clin J Am Soc Nephrol. 2012;7:712-9.

35. Matsuo S, Imai E, Horio M, Yasuda Y, Tomita K, Nitta K, et al. Revised equations for estimated GFR from serum creatinine in Japan. Am J Kidney Dis. 2009;53:982-92.

36. Knaus WA, Draper EA, Wagner DP, Zimmerman JE. APACHE II: a severity of disease classification system. Crit Care Med. 1985;13:818-29.

37. Semler MW, Self WH, Wanderer JP, Ehrenfeld JM, Wang L, Byrne DW, et al. SMART Investigators and the Pragmatic Critical Care Research Group Balanced crystalloids versus saline in critically ill adults. N Engl J Med. 2018; 378:829-39.

38. Austin PC. Optimal caliper widths for propensity-score matching when estimating differences in means and differences in proportions in observational studies. Pharm Stat. 2011;10:150-61.

39. Austin PC. Balance diagnostics for comparing the distribution of baseline covariates between treatment groups in propensity-score matched samples. Stat Med. 2009;28:3083-107.
40. Allgren RL, Marbury TC, Rahman SN, Weisberg LS, Fenves AZ, Lafayette RA, et al. Anaritide in acute tubular necrosis. Auriculin Anaritide Acute Renal Failure Study Group. N Engl J Med. 1997;336:828-34.

41. Lewis J, Salem MM, Chertow GM, Weisberg LS, McGrew F, Marbury TC, et al. Atrial natriuretic factor in oliguric acute renal failure. Anaritide Acute Renal Failure Study Group. Am J Kidney Dis. 2000;36:767-74.

42. Swärd K, Valsson F, Odencrants P, Samuelsson O, Ricksten SE. Recombinant human atrial natriuretic peptide in ischemic acute renal failure: $a$ randomized placebo-controlled trial. Crit Care Med. 2004;32:1310-5.

43. Mitaka C, Ohnuma T, Murayama T, Kunimoto F, Nagashima M, Takei T, et al. JAPAN Investigators Effects of low-dose atrial natriuretic peptide infusion on cardiac surgery-associated acute kidney injury: a multicenter randomized controlled trial. J Crit Care. 2017;38:253-8.

\section{Publisher's Note}

Springer Nature remains neutral with regard to jurisdictional claims in published maps and institutional affiliations.
Ready to submit your research? Choose BMC and benefit from:

- fast, convenient online submission

- thorough peer review by experienced researchers in your field

- rapid publication on acceptance

- support for research data, including large and complex data types

- gold Open Access which fosters wider collaboration and increased citations

- maximum visibility for your research: over $100 \mathrm{M}$ website views per year

At BMC, research is always in progress.

Learn more biomedcentral.com/submissions 